\title{
BRIEF COMMUNICATION OPEN Hidden biofilms in a far northern lake and implications for the changing Arctic
}

\author{
Vani Mohit ${ }^{1,2,3,4}$, Alexander Culley ${ }^{2,3}$, Connie Lovejoy ${ }^{1,3,4}$, Frédéric Bouchard ${ }^{5}$ and Warwick F. Vincent ${ }^{1,4}$
}

Shallow lakes are common across the Arctic landscape and their ecosystem productivity is often dominated by benthic, cyanobacterial biofilms. Many of these water bodies freeze to the bottom and are biologically inactive during winter, but full freezeup is becoming less common with Arctic warming. Here we analyzed the microbiome structure of newly discovered biofilms at the deepest site of a perennially ice-covered High Arctic lake as a model of polar microbial communities that remain unfrozen throughout the year. Biofilms were also sampled from the lake's shallow moat region that melts out and refreezes to the bottom annually. Using high throughput small subunit ribosomal RNA sequencing, we found more taxonomic richness in Bacteria, Archaea and microbial eukaryotes in the perennially unfrozen biofilms compared to moat communities. The deep communities contained both aerobic and anaerobic taxa including denitrifiers, sulfate reducers, and methanogenic Archaea. The water overlying the deep biofilms was well oxygenated in mid-summer but almost devoid of oxygen in spring, indicating anoxia during winter. Seasonally alternating oxic-anoxic regimes may become increasingly widespread in polar biofilms as fewer lakes and ponds freeze to the bottom, favoring prolonged anaerobic metabolism and greenhouse gas production during winter darkness.

npj Biofilms and Microbiomes (2017)3:17; doi:10.1038/s41522-017-0024-3

Thick biofilms (microbial mats) dominated by cyanobacteria occur in marine and freshwater habitats, and are especially well developed in extreme aquatic environments, including in the Arctic $^{1}$ and Antarctica. ${ }^{2}$ These biofilms have a complex structural organization that facilitates nutrient recycling, ${ }^{3}$ and they often dominate ecosystem biomass ${ }^{2}$ and biological production ${ }^{1,4}$ in the shallow lakes and ponds that are a major feature of the Arctic landscape. ${ }^{5}$ Although many of these high latitude water bodies freeze to the bottom during winter darkness, recent climate warming has led to reductions in bedfast ice, ${ }^{6}$ allowing microbial communities to persist in liquid water throughout the year. Our aim in the present study was to evaluate how this transition from seasonally frozen to perennially unfrozen conditions might affect the microbiome structure of Arctic biofilms, and the associated potential for biogeochemical processes.

We focused our sampling on Ward Hunt Lake (WHL) that harbors both seasonally frozen and perennially unfrozen microbial biofilms. WHL is the most northern lake in Canada, and is located in the northern Ellesmere Island region, $770 \mathrm{~km}$ from the North Pole (Fig. 1a). Previous studies ${ }^{1,7,8}$ at WHL have focused on benthic biofilms in the shallow moat of open water that forms in summer (Fig. 1b) and that refreezes to the lake sediment in early winter. It was assumed that benthic communities were restricted to this moat area because earlier ice coring in the central part of the lake had recorded $3.5-4.3 \mathrm{~m}$ of ice that extended to the lake bed. However, ground penetrating radar surveys ${ }^{9}$ revealed areas in the lake with up to $8 \mathrm{~m}$ of water below the maximum recorded ice thickness. In 2014, an extensive benthic biofilm was discovered in this deep, perennially ice-covered zone of WHL (Supplementary Video 1), and was sampled the following year.
We hypothesized that the deep biofilm communities of WHL would have a lower alpha-diversity than the moat biofilms because they would be dominated by microbial specialists that were adapted to a low solar energy regime caused by the thick perennial ice, combined with low nutrient conditions in this oligotrophic lake. In contrast, the moat habitat is exposed to full sunlight in summer, and receives direct nutrient subsidies via water tracks that discharge into it from the permafrost catchment; these warm (up to $8.8^{\circ} \mathrm{C}$ ) inflows may be mostly restricted to the moat zone and outflow, while the offshore waters are inversely stratified and typically $<4{ }^{\circ} \mathrm{C} .{ }^{9}$. To test this hypothesis of contrasting diversity, we analyzed three samples from each lake region (deep and moat microbial biofilms). DNA and RNA were extracted from the upper 3 to $5 \mathrm{~mm}$ (Fig. 1c-e) of the mats for high-throughput Illumina MiSeq amplicon sequencing that targeted variable regions of the small subunit ribosomal RNA (rRNA from complementary DNA (cDNA)) and the SS rRNA genes (rDNA from DNA). Detailed methods for collection, extraction, domain specific primers, and amplification steps are provided in the Supplementary Methods online. Raw reads were quality controlled and clustered into operational taxonomic units (OTUs) (Supplementary Table S1) with the UPARSE pipeline ${ }^{10}$ and these were further analyzed in QIIME ${ }^{11}$ (Supplementary methods). Raw bacterial, archaeal, and microbial eukaryote reads are available from the NCBI sequence read archive (SRA accession SRP078933).

This analysis of the WHL deep microbiome revealed a phylogenetic composition that differed markedly from the moat biofilms (Fig. 2). We found a high proportion of active OTUs in both communities, with the rRNA OTUs accounting for $72-88 \%$ of

\footnotetext{
${ }^{1}$ Département de biologie \& Centre d'études nordiques (CEN), Université Laval, Québec, QC G1V 0A6, Canada; ${ }^{2}$ Département de biochimie, de microbiologie et de bioinformatique, \& Centre d'études nordiques (CEN), Université Laval, Québec, QC G1V 0A6, Canada; ${ }^{3}$ Institut de biologie intégrative et des systèmes (IBIS), Université Laval, Québec,

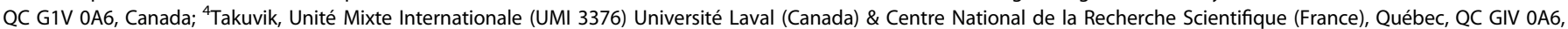
Canada and ${ }^{5}$ Centre Eau Terre Environnement, Institut national de la recherche scientifique (INRS), Centre d'études nordiques (CEN), Québec, QC G1K 9A9, Canada Correspondence: Warwick F. Vincent (warwick.vincent@bio.ulaval.ca)
}

Received: 5 March 2017 Revised: 7 June 2017 Accepted: 9 June 2017

Published online: 06 July 2017 

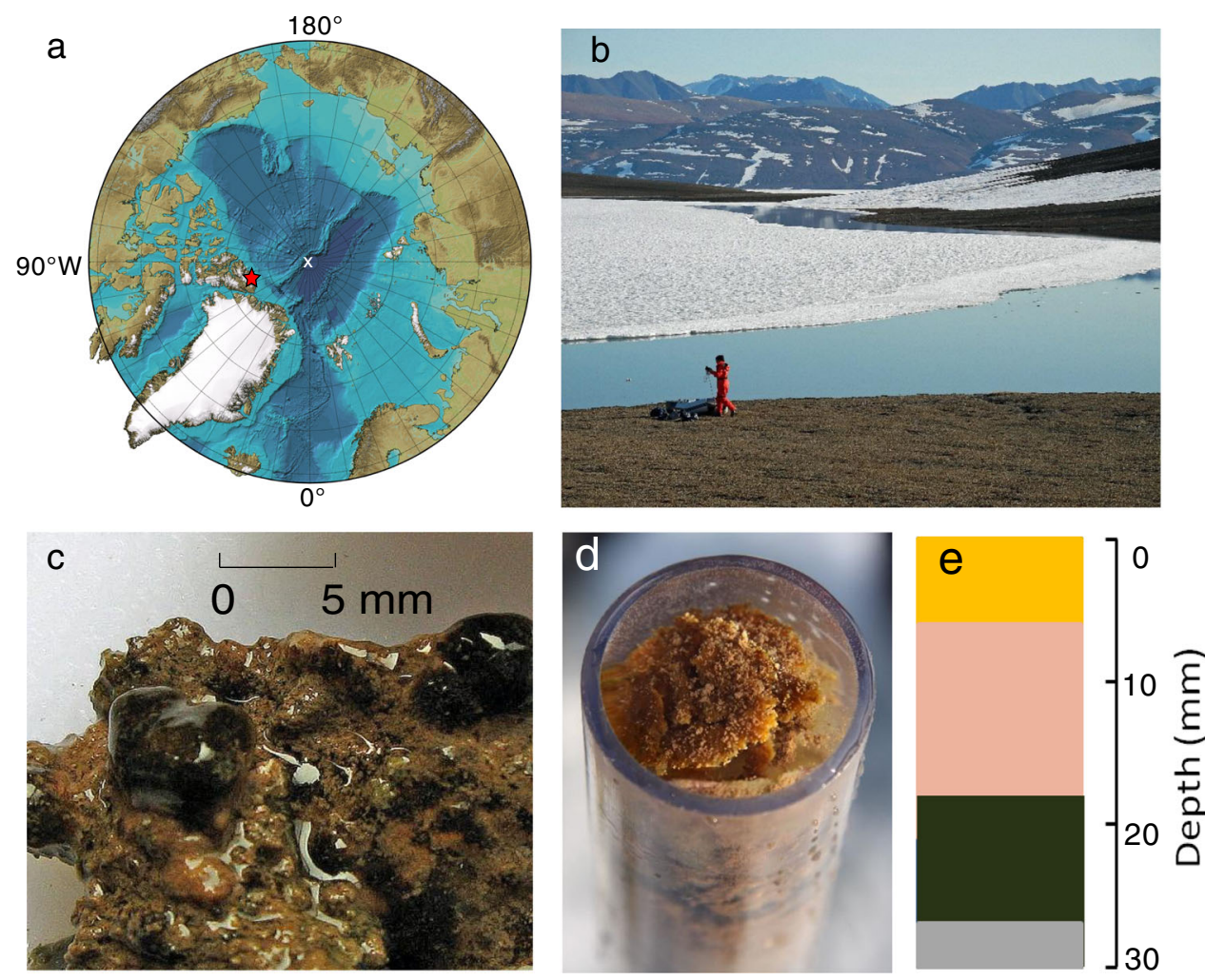

Fig. 1 The high Arctic sampling site and biofilms. a Location of Ward Hunt Lake (red star) relative to the North Pole (white cross); the base map is the International Bathymetric Chart of the Arctic Ocean (IBCAO) of the Intergovernmental Oceanographic Commission (IOC), version 3.0 released in the public domain on 8 June $2012 ;{ }^{20}$ b Ward Hunt Lake in mid-July 2015 showing the littoral open water zone (moat) and multiyear ice over the deeper waters of the lake; c Shallow biofilm over the rocks in the moat zone; d Sample of the deep biofilm in a mini-Glew sediment core ( $38 \mathrm{~mm}$ diameter) from $10 \mathrm{~m}$ depth; and e Schematic diagram of the biofilm color zonation (description in Supplementary Results)

the rDNA OTUs (Supplementary Table S2). Results from the phylogenetic clustering (Fig. 2 and Supplementary Fig. S1) and net relatedness indices (Supplementary Fig. S2) were consistent with habitat filtering ${ }^{12}$ (environmental selection of specific genotypes). Taxon abundances that differed by habitat (Fig. 2) included pennate diatoms, which were the predominant eukaryotes in the deep biofilms. Diatoms also tend to be abundant in Antarctic lake mats found under perennial ice $\operatorname{cover}^{13,14}$ and are known to tolerate a range of light conditions, with a potential for heterotrophic growth when light becomes limiting. ${ }^{15}$ In contrast, heterotrophic ciliates were the dominant microbial eukaryotes in the moat mats, suggesting a more active microbial food web and dominance of heterotrophy, with ciliates grazing on other eukaryotes and bacteria. ${ }^{16,17}$

Cyanobacteria were the most abundant bacteria in both deep and moat communities in WHL (Fig. 2), but differences in the cyanobacterial assemblages were observed between the two habitats (Supplementary Fig. S3). Leptolyngbya (Supplementary Fig. S3) was the most abundant cyanobacterial genus, accounting for $64-65 \%$ of cyanobacterial RNA reads in both communities. Leptolyngbya is a filamentous, globally distributed genus found in tropical, ${ }^{18}$ temperate, ${ }^{19}$ and polar microbial mats. ${ }^{4}$ At a finer taxonomic scale, many of the abundant OTUs were found to be closely related to Antarctic cyanobacteria (Supplementary Fig. S4), consistent with the global distribution of cold-dwelling ecotypes of cyanobacteria. ${ }^{7}$

Similar to Antarctic lake communities, ${ }^{4}$ potentially nitrogen-fixing cyanobacteria of the order Nostocales were rare in the deep biofilms $(<0.01 \%$ of bacterial reads) but abundant in the moat communities (6.2 \%; Supplementary Fig. S3), that might indicate N-limitation or greater relative phosphorus availability in the moat area. As a result of this taxonomic distribution, the PICRUSt analysis of the CDNA reads predicted a greater percentage of the nitrogenase (nifH) gene in the moat microbiome (Supplementary Table S3).

Eukaryote and bacteria OTU Chao1 richness estimates for the deep mat microbiome were high relative to the moat biofilms (Fig. 2). Compared to the moat biofilms, there were more bacterial taxa normally associated with anaerobic conditions in the deep biofilms, including sulfate-reducing delta-proteobacteria, Chloroflexi, WS3, GN04, Spirochaetes, Clostridia, denitrifying genus Thiobacillus (Supplementary Fig. S5) and anaerobic methanogenic Archaea. By association, these and other taxa in the deep mats would have genes involved in denitrification and sulfate-reduction (PICRUSt results; Supplementary Table S3). Archaea were rare in the moat mats (Supplementary Results) and the presence of groups involved in methane cycling (e.g., Methanomicrobia; Fig. 2) along with methanotrophic bacteria (Supplementary Results) in the deep biofilms suggest a much larger potential for methane cycling in the deep communities.

In summer, the deep communities were in contact with well oxygenated water at the time of sampling, however, oxygen profiles indicated near-zero oxygen concentrations $(2.9 \%$ of air equilibrium) overlying the biofilms in spring (Supplementary Fig. S6), and anoxia is, therefore, likely during winter darkness. Microzones of anoxia could persist in the biofilms during summer, as reported in temperate systems. ${ }^{19}$ Oxygen availability has been shown to have a structuring effect on mat communities in Antarctic ponds, ${ }^{4}$ and the seasonal fluctuations in both bottom water and biofilm oxygen may operate similarly in WHL, ensuring the persistence of anaerobic taxa in the deep biofilms through much of the year while aerobic taxa become active in summer. In contrast to the deep zone of the lake that does not freeze to the 

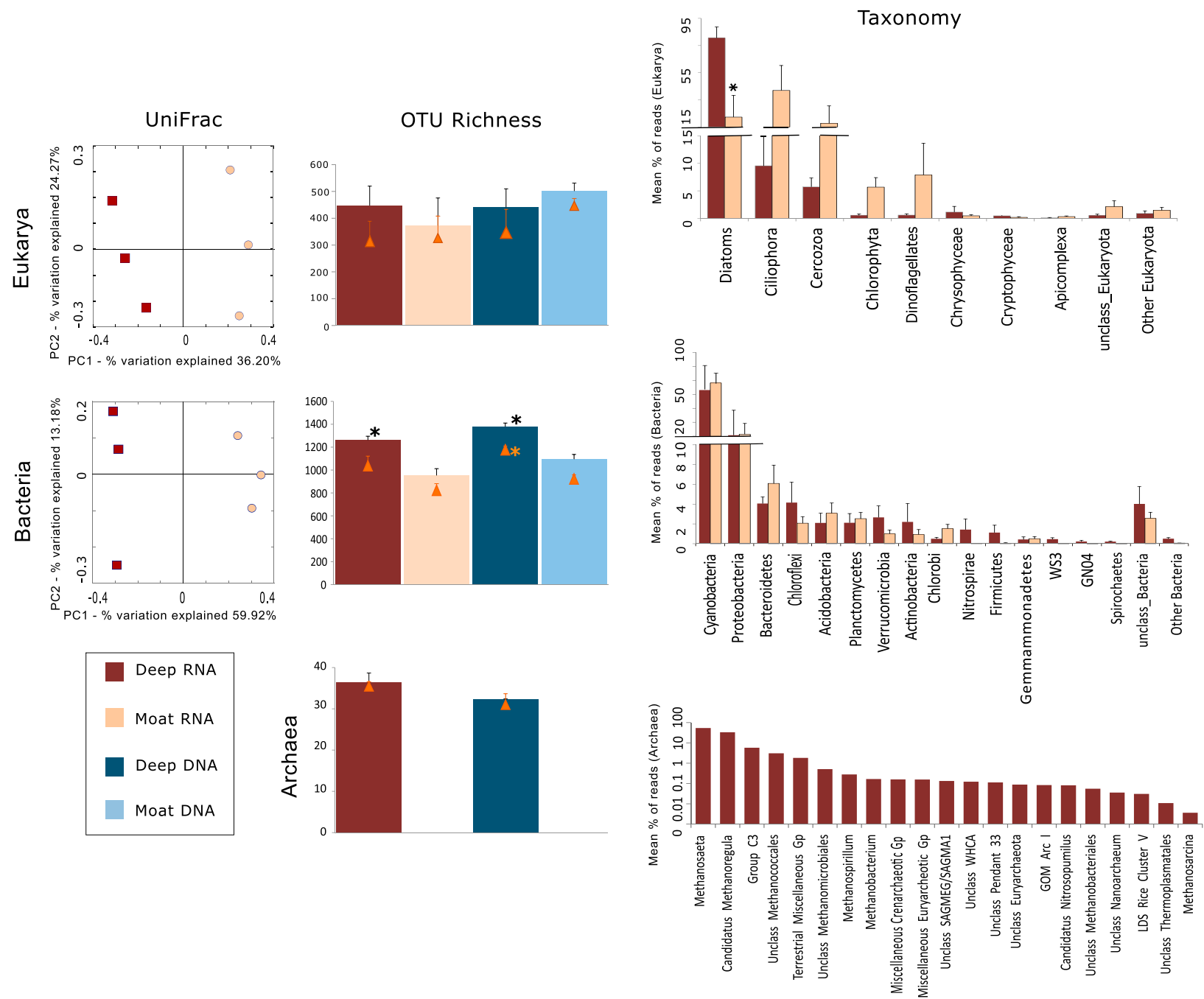

Fig. 2 Comparison of microbiome structure in the deep and moat biofilms in Ward Hunt Lake. Left panel: PCoA plots showing the clustering of eukaryotic and bacterial rRNA samples according to the unweighted UniFrac metrics. Middle panel: Bar chart showing the Chao 1 richness indices with standard error bars for triplicate rRNA and rDNA samples. Observed OTUs (filled triangles) with standard error bars are also indicated. Right panel: Taxonomic distribution for Eukarya (major groups), Bacteria (phyla) and Archaea (genera). Standard error bars are also shown. Asterisks indicate significant differences between deep vs. moat samples ( $t$-test, $p<0.05)$. The PCoA and taxonomic results shown are for the rRNA analysis; rDNA results are given in Supplementary Fig. S1

bottom in winter, the water column of the moat freezes solid each year and there is no liquid water during winter darkness to allow such alternation of oxic and anoxic niches for microbial activation and growth. There is presently no summer bedfast ice in the lake, and, therefore, no benthic sites that remain frozen throughout the year.

Large changes in ice cover have already been observed throughout the Arctic, with fewer lakes freezing to the bottom as the thickness of winter ice decreases. ${ }^{6}$ WHL lost its ice cover on two occasions in recent years, ${ }^{9}$ and a shift from multi-year ice to full ice-out conditions in summer could expand the habitat for communities that remain active during winter. The increased prevalence of liquid water conditions during winter darkness will likely favor anaerobic processes in the benthic microbiomes of Arctic lakes, and the resultant increases in methane production and denitrification will need to be accounted for in global carbon and nitrogen budgets. All of these aspects will require additional studies throughout the circumpolar North to determine whether benthic anoxia is a general feature of lakes without bedfast ice during the winter dark season, and to evaluate whether these environments support a diverse biofilm community of aerobes and anaerobes, as observed here at WHL.

\section{DATA AVAILABILITY}

Sequence data have been deposited in the NCBI sequence read archive (SRA accession SRP078933). The environmental data are available in the Nordicana D archive (doi: 10.5885/45445CE7B8194).

\section{ACKNOWLEDGEMENTS}

This research is part of the long-term program Northern Ellesmere Island in the Global Environment (NEIGE). We acknowledge funding support from the Natural Sciences and Engineering Research Council of Canada (NSERC) including the Discovery Frontiers project ADAPT; the Fonds de Recherche du Québec-Nature et Technologies (FQRNT); the ArcticNet Network of Centres of Excellence (Northern Frontier); and the program Sentinel North financed by the Canada First Research Excellence Fund (CFREF). We thank the Genomics Analysis Platform of the Institut de biologie intégrative et des systèmes (IBIS) of Université Laval led by B. Boyle for sequencing advice and support. Computing support was provided by the bioinformatics platform at IBIS. We also thank D. Sarrazin, M. Paquette, P. N. Bégin, and M. Labbé for their help in the field, A. Toperoff for editing the underwater video, A. Vigneron, J. Comte, and three anonymous referees for their comments and suggestions on the manuscript, the Polar Continental Shelf Program for logistic support and Parks Canada for use of their facilities at Quttinirpaaq National Park. 


\section{AUTHOR CONTRIBUTIONS}

V.M., A.C., C.L., and W.F.V. designed the research. V.M., A.C., W.F.V, and F.B. performed the research, V.M. analyzed the data. V.M., W.F.V., C.L., A.C, and F.B. wrote the paper.

\section{ADDITIONAL INFORMATION}

Supplementary Information accompanies the paper on the npj Biofilms and Microbiomes website (doi:10.1038/s41522-017-0024-3).

Competing interests: The authors declare that they have no competing financial interest.

Publisher's note: Springer Nature remains neutral with regard to jurisdictional claims in published maps and institutional affiliations.

\section{REFERENCES}

1. Lionard, M., Péquin, B., Lovejoy, C. \& Vincent, W. F. Benthic cyanobacterial mats in the High Arctic: multi-layer structure and fluorescence responses to osmotic stress. Front. Microbiol. 3, 140 (2012).

2. Andersen, D. T., Sumner, D. Y., Hawes, I., Webster-Brown, J. \& Mckay, C. P. Discovery of large conical stromatolites in Lake Untersee, Antarctica. Geobiology 9, 280-293 (2011).

3. Smith H. J. et al. Biofilms on glacial surfaces: hotspots for biological activity. $n p j$ Biofilms Microbiomes 2. doi:10.1038/npjbiofilms.2016.8 (2016).

4. Jungblut, A. D. et al. Microbial mat communities along an oxygen gradient in a perennially ice-covered Antarctic lake. Appl. Environ. Microbiol. 82, 620-630 (2016).

5. Rautio, M. et al. Shallow freshwater ecosystems of the circumpolar Arctic. Ecoscience 18, 204-222 (2011)

6. Surdu, C. M., Duguay, C. R., Brown, L. C. \& Fernández Prieto, D. Response of ice cover on shallow lakes of the North Slope of Alaska to contemporary climate conditions (1950-2011): Radar remote-sensing and numerical modeling data analysis. Cryosphere 8, 167-180 (2014).

7. Jungblut, A. D., Lovejoy, C. \& Vincent, W. F. Global distribution of cyanobacterial ecotypes in the cold biosphere. ISME J. 4, 191-202 (2010)

8. Bonilla, S., Villeneuve, V. \& Vincent, W. F. Benthic and planktonic algal communities in a high arctic lake: Pigment structure and contrasting responses to nutrient enrichment. J. Phycol. 41, 1120-1130 (2005).

9. Paquette, M., Fortier, D., Mueller, D. R., Sarrazin, D. \& Vincent, W. F. Rapid disappearance of perennial ice on Canada's most northern lake. Geophys. Res. Lett. 42, 1433-1440 (2015).
10. Edgar, R. C. UPARSE: highly accurate OTU sequences from microbial amplicon reads. Nat. Methods 10, 996-998 (2013).

11. Caporaso, J. G. et al. QIIME allows analysis of high-throughput community sequencing data. Nat. Methods 7, 335-336 (2010).

12. Webb, C. O., Ackerly, D. D., McPeek, M. A. \& Donoghue, M. J. Phylogenies and community ecology. Annu. Rev. Ecol. Syst. 33, 475-505 (2002).

13. Richardson, K., Beardall, J. \& Raven, J. A. Adaption of unicellular algae to irradiance: an analysis of strategies. New Phytol. 93, 157-191 (1983).

14. Hawes, I. \& Schwarz, A. M. Photosynthesis in an extreme shade environment: Benthic microbial mats from Lake Hoare, a permanently ice-covered Antarctic lake. J. Phycol. 35, 448-459 (1999).

15. Tuchman, N. C., Schollett, M. A., Rier, S. T. \& Geddes, P. Differential heterotrophic utilization of organic compounds by diatoms and bacteria under light and dark conditions. Hydrobiologia 561, 167-177 (2006).

16. Epstein, S. et al. Enumeration of sandy sediment bacteria: are the counts quantitative or relative? Mar. Ecol. Prog. Ser. 151, 11-16 (1997).

17. Hamels, I., Mussche, H., Sabbe, K., Muylaert, K. \& Vyverman, W. Evidence for constant and highly specific active food selection by benthic ciliates in mixed diatoms assemblages. Limnol. Oceanogr. 49, 58-68 (2004).

18. Palińska, K. A. et al. Opportunistic Cyanobacteria in benthic microbial mats of a tropical lagoon, Tikehau Atoll, Tuamotu Archipelago: minor in natural populations, major in cultures. Fottea 12, 127-140 (2012).

19. Lindemann, S. R. et al. The epsomitic phototrophic microbial mat of Hot Lake, Washington: community structural responses to seasonal cycling. Front. Microbiol. 4, 323 (2013).

20. Jakobsson, M. et al. The International Bathymetric Chart of the Arctic Ocean (IBCAO) Version 3.0. Geophys. Res. Lett. 39, L12609 (2012).

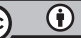

Open Access This article is licensed under a Creative Commons Attribution 4.0 International License, which permits use, sharing, adaptation, distribution and reproduction in any medium or format, as long as you give appropriate credit to the original author(s) and the source, provide a link to the Creative Commons license, and indicate if changes were made. The images or other third party material in this article are included in the article's Creative Commons license, unless indicated otherwise in a credit line to the material. If material is not included in the article's Creative Commons license and your intended use is not permitted by statutory regulation or exceeds the permitted use, you will need to obtain permission directly from the copyright holder. To view a copy of this license, visit http://creativecommons. org/licenses/by/4.0/.

(c) The Author(s) 2017 